\title{
Fair's Fair? Principles, Partisanship, and Perceptions of the Fairness of Campaign Rhetoric
}

\author{
DANIEL STEVENS, BARBARA ALLEN, JOHN SULLIVAN AND \\ ERIC LAWRENCE*
}

This article considers the role of principles in perceptions of what constitutes acceptable rhetoric in election campaigns. Previous research suggests that citizens use principles of what is an acceptable attack in campaigns when evaluating charges and countercharges, while acknowledging that under some circumstances citizens accept rhetoric that would seem to breach their principles. This research has not adequately considered how partisanship can affect a respondent's proclivity to call upon principles in assessing campaign rhetoric. This article draws on three original surveys to test competing models of the role of partisanship and finds robust results in support of a strong partisan bias. It concludes that it is not that citizens are resilient to violations of their principles, but that nearly the opposite is the case: citizens' sensitivity to attacks on their preferred candidate leads them to take a very partial view of when to apply their principles faithfully to a judgment and when not to.

Last week Gerlach's campaign said it stands by its ads that try to link one of Murphy's key supporters to the Taliban, rape, kidnapping and terrorist attacks. Murphy has repeatedly called on Gerlach to pull the ads, saying they are 'pure fiction' and 'insulting to voters' ... A Gerlach spokesman, John Gentzel, said that in this hard-fought campaign, the ads are valid ... 'We think it is fair' (Philadelphia Inquirer, 2 November 2004).

A new advertisement by Rick Perry takes a sharper tone than his previous ads, taking aim at President Obama's comment last weekend that American businesses had been 'a little bit lazy' in taking for granted that new investment would want to come to the United States ... But the ad takes Mr. Obama's remark out of context (New York Times, 17 November 2011).

Election campaigns such as those in the United States are full of the kinds of negative claims described in these recent contests for various offices; perhaps increasingly so. ${ }^{1}$ As political marketing techniques have come to characterize politics in other electoral systems too, ${ }^{2}$ questions about the effects of negativity in political exchange are more compelling than ever. These newspaper accounts also suggest that some attacks go too far: they are unfair in some way. 'Fairness', it appears, constitutes one criterion that voters may use to evaluate campaign ad claims. Indeed, although agreement about the impact of negativity remains elusive, ${ }^{3}$ political scientists appear to have settled on the idea that individuals hold principles of 'fairness' and what constitutes 'civility', as well as criteria such as

* University of Exeter; Carleton College; University of Minnesota; George Washington University, (emails D.P.Stevens@exeter.ac.uk, ballen@carleton.edu, jsull@umn.edu, edl@gwu.edu). Thanks to Justin Whitely Holmes, who was integral to the development of the 2004 survey, and to Deborah Jordan Brooks and Beth Miller for helpful comments and advice. Online appendices and replication data and syntax files are available at http://dx.doi.org/doi:10.1017/S0007123413000045.

${ }^{1}$ Geer 2006; Geer 2012.

${ }^{2}$ Lilleker and Lees-Marshment 2005.

${ }^{3}$ Lau, Sigelman, and Rovner 2007, p 1181. 
'relevance' in making judgments about political advertising claims. The consensus viewpoint goes further to claim that only when these principles are violated do we see distinct effects of negativity. ${ }^{4}$

Our research questions the validity of this latter claim. We agree that individuals have principles regarding what is a fair negative claim, and we demonstrate that they are enduring standards, but we also show that voters apply such principles to actual ads in a real election campaign inconsistently. How do principles such as fairness and civility - or other standards of evaluation, such as the relevance of a campaign claim - figure into citizens' definitions of acceptable election campaign rhetoric? We assess the influence of one criterion of evaluation fairness - on the distinctions citizens make between acceptable campaign criticism and unacceptable 'negative attacks' in three US presidential campaigns. We discover that a principle of fairness matters: individuals who think a criticism is unfair in principle are generally more likely to regard a specific instance of such criticism as also unfair. Yet we also find that voters apply their principle of fairness inconsistently when they evaluate the actual ad claims made by real candidates for elective office. These findings lead us to conclude that: (1) previous research on fairness, civility or other standards of evaluation overestimates the role played by the content (compared to the source) of an attack and (2) the notion of a public inured to the harshness of modern campaigns is a simplification of reality that inaccurately characterizes individuals' responses to negative critiques.

Our findings suggest that the presence of partisan cues can alter how negative advertising information is processed and used to evaluate candidates, thus affecting decisions about whether (and for whom) to vote. ${ }^{5}$ These results comport with studies that have acknowledged the importance of the congruence between an ad's sponsor and the partisanship of a viewer. Our work suggests, however, that a continuing focus on content over source will overlook an important factor in voter decision making. ${ }^{6}$ Whether partisan cues only influence attitudes toward information (for example, beliefs about its veracity, fairness or relevance) or indeed change how information is processed (for example, by varying the modality of cognition), empirical studies of assessments of fairness that omit information about the sponsoring party will sufficiently alter the context for judgment from that of an actual electoral contest so as to produce significantly biased conclusions.

To be clear, we are not denying that other studies have acknowledged the importance of the congruence between an ad's sponsor and the partisanship of a viewer; ${ }^{7}$ their foci are different to ours. We are saying that many studies continue to focus on content over source, however, for example by conducting experiments in which partisan cues are absent.

\section{PRINCIPLES, MOTIVATED REASONING AND PERCEPTIONS OF FAIRNESS}

Political practitioners and academics have been attracted to the notion that perception of the fairness or acceptability of a criticism is a major source of variation in the influence

4 Bartels 1998; Brooks and Geer 2007; Faucheux 1994, p 5; Freedman and Lawton 2000.

5 We examine negative advertising, but criticisms are also aired via other media, such as in speeches, news debates, direct mail and telephone calls. Motivated partisan reasoning is also likely to moderate the impact of fairness principles through these media.

${ }^{6}$ Lau, Sigelman, and Rovner (2007) survey such work in their most recent meta-analysis and confirm this supposition. The experimental methodology is not at issue; failing to consider partisanship is a matter of concern.

7 For example, Sides, Lipsitz and Grossmann 2010; Sigelman and Kugler 2003. 
of negative political messages. Ron Faucheux ${ }^{8}$ insists on the acceptability of 'going negative' - until it crosses the line and becomes unfair, deceptive or hateful; Larry Bartels ${ }^{9}$ contends that the 'largely misplaced' research and media focus on so-called negativity fails to distinguish the merely contentious from the 'nasty, inaccurate or unfair' in advertising. Kim Fridkin Kahn and Patrick Kenney claim that 'people distinguish between legitimate and tempered criticisms, on the one hand, and acrimonious and unjust criticisms, on the other hand'. ${ }^{10}$ Researchers not only contend that citizens make nuanced judgments about political advertising; they also note that they often learn from - and are stimulated by - negative information. ${ }^{11}$ Accordingly, when negative information fails to engage voters, it is because the attack goes too far and is perceived to be unfair or unacceptable, reducing the likelihood that offended voters will go to the polls. ${ }^{12}$

Recent studies of the impact of modern campaign rhetoric claim that citizens hold principles - including fairness ${ }^{13}$ and civility ${ }^{14}$ - that inform their judgments about various types of criticisms that are made about candidates for elective office. The association between fairness (as an indicator of an advertising claim's acceptability) with political participation has been demonstrated in the context of a real campaign. ${ }^{15}$ These principles, as well as other standards of evaluation such as the relevance of a given campaign claim, ${ }^{16}$ can inform citizens' judgments about which claims are acceptable or useful in evaluating the candidates. These studies have also helped distinguish between what citizens say about various types of claims and how claims they deem unacceptable may, nevertheless, influence their candidate evaluations. This distinction suggests that citizens may hold standards of evaluation, but that their principles also permit violations.

We echo the previous findings that individuals hold notions of what constitutes fair criticism in political advertising. ${ }^{17}$ Like other researchers, we find that respondents in our studies were more likely to tolerate issue-based criticisms than character-based criticisms, and that partisans tend to be more generous than non-partisans in their evaluations of what is fair game in a campaign. Our findings also show substantial agreement among respondents on the types of claims that, in the abstract, fall either within or outside the bounds of acceptability. This body of work indicates that it is appropriate to refer to norms such as fairness and civility as 'principles', and that important generalizations may be made about the articulated bounds of propriety in campaign rhetoric for American political culture.

Despite the significant advances of previous research on two of the most important questions asked about campaign discourse - (1) what constitutes 'negative', unfair, and uncivil rhetoric and (2) how such communication might influence electoral behavior - in

${ }^{8}$ Faucheux 1994, p 5 .

${ }^{9}$ Bartels 1998.

${ }_{10}$ Kahn and Kenney 1999, p 884; see also Fridkin and Kenney 2008; Jamieson 2000.

11 Geer 2006; Marcus, Neuman, and MacKuen 2000.

${ }^{12}$ Kahn and Kenney 1999.

${ }^{13}$ Freedman and Lawton 2000; Stevens et al. 2008.

${ }^{14}$ Brooks and Geer 2007; Fridkin and Kenney 2011; Mutz and Reeves 2005.

${ }^{15}$ Stevens et al. 2008.

${ }_{17}^{16}$ Fridkin and Kenny 2008; Fridkin and Kenny 2011.

${ }^{17}$ There are similar norms for what constitutes civil and uncivil exchanges (Brooks and Geer 2007). See online Appendix III Table A-1 for evidence of the stability of fairness principles, which are comparably stable over time to partisanship. 
many cases researchers continue to draw conclusions about ad effects from research conducted in a contextual vacuum, in which a candidate from one unidentifiable party attacks a candidate from another unidentifiable party. This research portrays a public that has been habituated to rough campaign rhetoric and is able to maintain principles of fairness and civility, resisting the effects of a negative campaign. Yet we actually know nothing about the ways that principles of acceptable rhetoric operate in the context of real campaign exchanges (or indeed, whether these principles matter at all). Nor do we know whether information about the source of a claim is relevant to the standard of evaluation that is used.

Suppose an individual believes that an advertisement criticizing a candidate's military record is, in principle, unacceptable. In a real campaign, this individual may be a partisan identifier and the candidate who is being criticized for his military record may be Democratic presidential candidate, John Kerry or Barack Obama, or the Republican incumbent (in 2004) George W. Bush. What happens then? We consider four competing models.

First, her judgment that criticizing a candidate's military record is beyond the pale may lead her to perceive such attacks on either candidate as unfair. We know that individuals have notions of what is fair in public discourse ${ }^{18}$ and political advertising, and that adherence to norms influences perceptions of what constitutes fair treatment in other realms such as legal conflict. ${ }^{19}$ Moreover, there is a great deal of evidence, both old and new, that individuals try to maintain cognitive consistency in their attitudes and behaviors. ${ }^{20}$ For these reasons, we might expect norms of fairness to be consistently applied, perhaps not by everyone but by many citizens.

We call this a 'No Partisan Bias' or Principles $=$ Practice model. It holds that the distinctions that individuals make between fair and unfair criticisms in principle (that is, in the absence of partisan labels) are applied evenly in practice: if the attack is unfair in principle it will also be unfair in practice, and if it is fair in principle it is also fair grounds for critique in a real campaign. ${ }^{21}$ Returning to our hypothetical, consider an individual who is a Republican identifier viewing, in one scenario, criticism of John Kerry's military service record and, in another scenario, criticism of George W. Bush's military service record. She may be psychologically motivated to maintain a different kind of consistency, arriving at the conclusion that while the attack on George W. Bush's military record is objectionable, the attack on John Kerry's military record is in fact acceptable. This possible response reflects a type of consistency driven by a process of motivated reasoning in service of an evaluation that sits well with her partisan predispositions. Studies from political science and social psychology show that, rather than carefully weighing information to arrive at a judgment, individuals often adopt strategies of processing information that protect their predispositions. ${ }^{22}$ Motivated reasoning suggests that individuals encountering criticisms made in negative political advertising will draw on the cue of partisanship, either to infer the fairness of the criticisms (characterized as fair if

18 Gutmann and Thompson 1998; Mutz and Reeves 2005.

19 Tyler 1990.

20 Festinger 1957; Heider 1958; Simon, Snow, and Read 2004.

21 The concept of principled or biased information processing is distinct from persuasion. It is not that partisans are equally likely to be persuaded by these criticisms, but that they are as likely as non-partisans to apply their principles of fairness consistently.

22 Braman and Nelson 2007; Fischle 2000; Kunda and Sinclair 1999; Lavine, Lodge, and Freitas 2005; Rudolph 2006. 
they criticize the opponent and unfair if they criticize the preferred candidate) or to ignore the content of the criticisms and rely only on partisan cues. For example, partisans receiving incongruent information may reason that the criticism is irrelevant to the election or that the source is too unreliable to be taken seriously. ${ }^{23}$

Nevertheless, motivated reasoning has its limit. Individuals are ultimately 'constrained by their ability to construct seemingly reasonable justifications for these conclusions'. ${ }^{24}$ This possibility leads us to suggest three models of partisan bias. One potential constraint on motivated reasoning is that "norm violations should generate a negative reaction, much as they do when people are exposed to such violations in real life'. ${ }^{25}$ This limitation suggests that where norms of fairness are violated (that is, individuals are exposed to criticism that they regard as unfair in principle) partisan motivated reasoning may be inhibited. Faced with a topic of criticism that they unequivocally consider unfair, these individuals may give no consideration to whether they share the partisanship of the sponsor or target; the subject matter is simply off limits for them. If there is no violation of such a normative constraint, however (that is, the criticism is seen as fair in principle), partisans for whom the criticism is incongruent are not so constrained: their affinity to the shared partisanship of either the sponsor or the target is an important consideration. They can rationalize that in this instance (an attack on their preferred candidate) the criticism is unfair, which apparently violates their original principled assessment that this topic of criticism is fair game. We term this, the mildest version of partisan bias, the Weak Partisan Bias model. It is similar to the Principles $=$ Practice model in one respect: individuals who view a topic as fair in principle will, overall, be more likely than individuals who consider a topic as unfair in principle to judge actual criticism on that subject as fair in practice. However, when a criticism is judged as fair in principle, partisans for whom an actual criticism is congruent with their predispositions (for example, Republicans exposed to a criticism of Barack Obama) will be more likely to judge it as fair than partisans for whom an actual criticism is incongruent with their predispositions (for example, Democrats exposed to a criticism of Barack Obama).

But perhaps motivated reasoning is not so constrained by norm violations. Indeed, Redlawsk et al. ${ }^{26}$ show that motivated reasoning is resistant to large amounts of seemingly inconsistent information, suggesting a stronger kind of partisan bias. For individuals behaving according to a Strong Partisan Bias model, those who view a topic as fair in principle will again, overall, be more likely to view actual criticism on the topic as fair in practice than those who view a topic as unfair in principle. But beyond that, partisanship moderates the application of principle for the categories of unfair and fair criticism alike. Although a topic is judged off limits as a matter of principle, individuals exhibiting a strong partisan bias will be less likely to judge a criticism of their preferred candidate as fair than will be individuals for whom the attack is congruent with their partisanship. The Strong Partisan Bias model postulates that an individual who is confronted with an attack on the opposition may reason that, although the subject matter of the attack is usually out of

\footnotetext{
23 Counterarguments of this nature differ from relying solely on partisan cues, but both are examples of partisan-motivated reasoning: the cue of partisanship provides the affective basis on which to sustain a biased conclusion. These alternatives are observationally equivalent in terms of the impact of partisanship on perceptions of campaign criticisms; we do not distinguish between them here because our main initial interest is in the nature of the interaction of principles and partisanship.

24 Kunda 1990, p 480.

25 Mutz and Reeves 2005, p 6.

26 Redlawsk, Civettini, and Emerson 2010.
} 
bounds, in this case, applied to this (opposing) candidate, the topic of attack is legitimate, and the attack is fair: biased processing is likely to overrule the strict application of their principles, regardless of whether those principles say that the topic is unfair or fair grounds for criticism.

A variation on such partisan bias is the Only Partisan Bias model, which is similar to the Strong Partisan Bias model in that partisanship influences all individuals' judgments of the fairness of criticisms - both those who say a criticism is fair in principle and those who say a criticism is unfair in principle. But with the Only Partisan Bias model, principles of fairness themselves have no influence on judgments of the fairness of actual criticisms. Thus in the Only Partisan Bias model, knowing that a respondent viewed a topic of criticism as unfair or fair in principle is not predictive of their judgment of actual criticism on that topic as either unfair or fair.

\section{RESEARCH DESIGN AND ANALYSIS}

Testing the four models requires that we ascertain individuals' evaluations of the fairness of criticisms in principle and in practice. We conducted three random sample national telephone surveys that accomplished this aim in 2002, 2004 and 2008, completing more than 2,000 interviews (for details of the surveys, see Appendix I). Thus our findings have the virtue of not being tied to a particular election context, such as an incumbent facing re-election, or particular candidates. The first survey took place from March to June 2002, the second in October 2004 and the third in October 2008. In 2002 we interviewed 705 American citizens who were eligible to vote; in 2004 we surveyed 510 citizens eligible to vote and re-interviewed 210 of the 705 respondents from the 2002 sample; in 2008 we interviewed 520 citizens eligible to vote and re-interviewed 261 respondents from the earlier samples. (See Table A-2 of online Appendix III for sample characteristics and comparisons to census and American National Election Study data). We pooled the new respondents and re-interviews in 2004 and 2008. Analyzing only the new respondents makes no difference to our substantive conclusions about each election.

Our surveys first replicated the questions used by Freedman and Lawton: ${ }^{27}$ whether it is fair or unfair for candidates to criticize an opponent in campaign ads on various issue positions, matters of character and other candidate constructs. In the next stage of questioning we injected partisanship into candidates' criticisms by asking about the fairness of some specific examples of these criticisms of the opponent made by the presidential candidates and their supporters during the 2000, 2004 and 2008 elections. We randomized the order in which we asked these questions. We did not inform respondents that they were specific examples of the same charges whose fairness they had previously been asked to assess in principle; to the extent that respondents recognized that they were, it is likely that they would try to keep their answers consistent, biasing results toward the Principles $=$ Practice model. Table A-3 of online Appendix III provides a summary of the abstract and specific attacks presented to respondents across the surveys: thirty-one specific criticisms on nine subjects whose fairness they had first been asked to evaluate in principle (Appendix IV presents the exact wording). We thus obtained judgments of fairness in principle and in practice, which enable us to evaluate the validity of the four models.

Our approach to analyzing the data is to estimate models that predict perceptions of fairness for each of the thirty-one specific criticisms covered in the three surveys, where

${ }^{27}$ Freedman and Lawton 2000. 
the perception of attacks on George W. Bush (in 2000 and 2004), John McCain, Al Gore, John Kerry and Barack Obama is the dependent variable, coded as 'fair' or 'unfair'. ${ }^{28}$ The key predictors that test the different models are, with variable labels in parentheses:

(1) Perceptions of the fairness of the criticism in principle (Fairness of the Criticism in Principle, a dichotomous $0-1$ variable)

(2) Whether the partisanship of the respondent is congruent or incongruent with the criticism (Partisanship Congruent with Criticism, coded 1 if a criticism is congruent and 0 if it is not: a criticism is congruent if a respondent is a Democrat and the target of the criticism is George W. Bush or John McCain, or if the respondent is a Republican and the target of the criticism is Al Gore, John Kerry or Barack Obama)

(3) The interaction between fairness of the criticism in principle and congruency of partisanship (Fairness in Principle $\times$ Partisanship Congruent with Criticism)

We also include variables for Independents (Independent) and for the interaction between Independents and perceptions of the fairness of a criticism in principle (Fairness in Principle $\times$ Independent).

Fairness in Principle is the effect of fairness principles on partisans for whom a criticism is incongruent (that is, a Democrat when the target of the criticism is Al Gore, John Kerry or Barack Obama, or a Republican when the target of the criticism is George W. Bush or John McCain). Thus the interaction term Fairness in Principle $\times$ Partisanship Congruent with Criticism shows how sharing the partisanship of a criticism's sponsor moderates the influence of principles in evaluating ad claims by affecting the judgments of those who identify a criticism as fair in the abstract. (Fairness in Principle $\times$ Independent shows the moderating influence of identifying as an Independent). Including interaction variables means that the 'main effects' of the variables comprising the interactions (the constituent terms) capture the effects of a variable when the other variable in the interaction equals zero. ${ }^{29}$

\section{RESULTS}

Rather than present the results from all thirty-one specific criticisms, we display illustrative findings from each survey for two types of criticisms: that the candidate either 1) talks one

${ }^{28}$ The data confirm conventional wisdom about citizens' perceptions of the kinds of critiques that are fair in principle in two important ways. First, there is a tendency for partisans to be more willing than Independents to allow that genres of critique are fair game. Secondly, Republican and Democratic identifiers largely endorse the same principles regarding what is fair game for negative campaign advertising. Of the twenty-three examples, Republicans and Democrats differed at statistically significant levels for nine. Four of those differences appeared in the 2008 survey. All nine instances showed Republicans judging the subject of a particular attack to be fairer in principle than Democrats, perhaps because, even in the abstract, specific examples came readily to mind (for example, 'scandals of associates' and the criticisms of Obama for his relationships with Jeremiah Wright and Bill Ayers), meaning that our subjects responded as motivated partisans. Such differences in orientation would weaken support for the Strong and Only Partisan Bias models because partisan differences in the application of principles to specific criticisms would already be reflected in differential endorsements of principles. Summary figures are provided in online Appendix III Table A-4.

${ }^{29}$ We also estimated models in which we operationalized partisanship with three-point scales for Republican intensity and Democrat intensity - from strong, through weak, to leaning - and with fairness as a four-point scale rather than a binary. The results were similar. We present the more easily interpretable estimates using dummy variables here. All other estimates are available from the authors on request. 
way but votes another or 2) accepts campaign contributions from special interests. Focusing on two examples of criticisms permits us to present a detailed analysis of the effects of our three key predictors on perceptions of the fairness of actual ad claims and the implications of this analysis for the role of principles in fairness judgments. We display these detailed findings in Tables 1 and 2 and in Figure 1, and summarize the analysis of the remaining nineteen criticisms in Figure 2.

Table 1 presents estimates for criticisms of George W. Bush and Al Gore from the 2000 election, George W. Bush and John Kerry from the 2004 election, and John McCain and Barack Obama in 2008 that were related to 'talking one way but acting or voting another'. These critiques covered charges such as George W. Bush claiming credit in 2000 for a law he had opposed as governor of Texas, John Kerry touting fiscal responsibility while having voted for the largest tax increase in American history and John McCain opposing and then supporting Bush administration tax cuts.

The key variables appear in the first three rows of Tables 1 and 2. We indicate whether the coefficients for variables are statistically significantly different from zero at levels of up to $\mathrm{p}<0.10$ in one-tailed tests. Our estimates control for other individual-level variables that the literature indicates are important: trust in the federal government as an indicator of views of government, political expertise and generation. Studies of trust in government suggest two plausible effects: (1) citizens who view government positively may also perceive the kinds of charges that are the common currency of negative political advertising to be among the most unfair $^{30}$ or (2) to the extent that trust in the federal government is incumbent based, ${ }^{31}$ its influence on perceptions of fairness may depend on the target of the attack. Political expertise, which we measured by political knowledge and frequency of newspaper readership, may foster a greater tolerance of negative criticisms. ${ }^{32}$ Generation, measured by age cohorts, may show signs of 'life-cycle effects' in which, along with electoral interest and participation, perceptions of the fairness of negative exchanges increase as a cohort ages; or perhaps older cohorts may have 'seen it all' but still reject caustic public discourse and a younger generation that has perhaps become habituated to the vitriolic public criticism that is modeled in the media to which they pay attention. All variables were coded from 0 to 1 (see online Appendix II). ${ }^{33}$

Beginning with Table 1, it is immediately apparent from all six sets of estimates that principles of fairness influence judgments of specific criticisms, which are represented by the positive and statistically significant coefficients in five of the models for Fairness of the Criticism in Principle.

Partisanship also moderates the influence of principles of fairness - shown by the impact of the variables Partisanship Congruent with Criticism and Fairness in Principle $\times$ Partisanship Congruent with Criticism. But which of the partisan models is most strongly supported?

${ }^{30}$ Ansolabehere and Iyengar 1995.

31 Miller 1974.

${ }^{32}$ Kahn and Kenny 1999.

${ }^{33}$ Controlling for age in years rather than generation makes no difference to our main results, but generations seem to better capture what often appear to be non-linear effects of age that are not well represented by linear or quadratic specifications. Additional specifications in which we controlled for an array of other possible influences, including positive and negative perceptions of political advertising, frequency of watching local news, frequency of watching national news, external efficacy, sex, race and marital status (variables which had overwhelmingly statistically insignificant influences on perceptions of the fairness of attacks) produced the same results. 
та в LE 1 Influences on Perceptions of the Fairness of Criticizing Candidates for Talking One Way and Voting Another (Logit Models)

\begin{tabular}{|c|c|c|c|c|c|c|}
\hline Independent variable & $\begin{array}{l}\text { George W. Bush } \\
(2000)\end{array}$ & $\begin{array}{l}\mathrm{Al} \\
\text { Gore }\end{array}$ & $\begin{array}{l}\text { George W. } \\
\text { Bush (2004) }\end{array}$ & $\begin{array}{l}\text { John } \\
\text { Kerry }\end{array}$ & $\begin{array}{l}\text { John } \\
\text { McCain }\end{array}$ & $\begin{array}{l}\text { Barack } \\
\text { Obama }\end{array}$ \\
\hline (1) Fairness of the criticism in principle & $1.06(0.28)^{* *}$ & $0.75(0.26)^{* *}$ & $-0.09(0.36)$ & $0.89(0.26)^{* *}$ & $0.49(0.29)^{*}$ & $0.44(0.26)^{\#}$ \\
\hline (2) Partisanship congruent with criticism & $0.54(0.29)^{*}$ & $0.44(0.29)^{\#}$ & $2.26(0.39)^{* *}$ & $1.08(0.35)^{* *}$ & $1.04(0.32)^{* *}$ & $1.66(0.33)^{* *}$ \\
\hline $\begin{array}{l}\text { (3) Fairness in principle } \times \text { Partisanship } \\
\text { congruent with criticism }\end{array}$ & $0.85(0.41)^{*}$ & $0.27(0.38)$ & $0.99(0.49)^{*}$ & $1.01(0.44)^{*}$ & $0.25(0.38)$ & $0.54(0.39)^{\#}$ \\
\hline Independent & $0.21(0.37)$ & $-0.38(0.36)$ & $1.80(0.64)^{* *}$ & $1.52(0.56)^{* *}$ & $0.39(0.48)$ & $1.00(0.47)^{*}$ \\
\hline Fairness in principle $\times$ Independent & $0.49(0.53)$ & $1.15(0.52)^{*}$ & $0.02(0.74)$ & $0.04(0.72)$ & $0.93(0.66)^{\#}$ & $0.88(0.63)^{\#}$ \\
\hline \multicolumn{7}{|l|}{ View of Government } \\
\hline Trust in government & $-0.05(0.35)$ & $-0.18(0.34)$ & $-1.29(0.54)^{* *}$ & $0.18(0.51)$ & $0.39(0.47)$ & $0.02(0.49)$ \\
\hline \multicolumn{7}{|l|}{ Political Expertise } \\
\hline Political knowledge & $0.73(0.35)^{*}$ & $0.33(0.33)$ & $0.37(0.42)$ & $-0.51(0.39)$ & $0.82(0.34)^{* *}$ & $0.19(0.35)$ \\
\hline Newspaper readership & $-0.22(0.24)$ & $-0.32(0.23)^{\#}$ & $0.10(0.28)$ & $-0.72(0.28)^{* *}$ & $-0.21(0.20)$ & $0.36(0.21)^{*}$ \\
\hline \multicolumn{7}{|l|}{ Generation } \\
\hline New deal & $-0.68(0.41)^{\#}$ & $-0.37(0.42)$ & $-0.31(0.44)$ & $-0.21(0.41)$ & $-0.71(0.37)^{*}$ & $-0.16(0.39)$ \\
\hline Cold War & $-0.32(0.28)$ & $-1.29(0.28)^{* *}$ & $-0.26(0.29)$ & $-0.19(0.27)$ & $-0.58(0.25)^{*}$ & $-0.11(0.25)$ \\
\hline Early boomer & $-0.27(0.26)$ & $-0.23(0.25)$ & $-0.01(0.30)$ & $0.46(0.29)^{\#}$ & $-0.74(0.26)^{* *}$ & $-0.16(0.26)$ \\
\hline Late boomer & $0.27(0.25)$ & $0.06(0.23)$ & $0.60(0.29)^{*}$ & $0.20(0.27)$ & $-0.60(0.24)^{* *}$ & $-0.23(0.24)$ \\
\hline Constant & $-0.80(0.40)^{*}$ & $-0.09(0.35)$ & $-0.63(0.54)$ & $-0.20(0.46)$ & $-0.60(0.44)^{\#}$ & $-1.39(0.40)^{* *}$ \\
\hline $\mathrm{N}$ & 634 & 630 & 640 & 626 & 733 & 734 \\
\hline Pseudo $\mathrm{R}^{2}$ & 0.14 & 0.11 & 0.28 & 0.20 & 0.09 & 0.18 \\
\hline Prob. $>\mathrm{Chi}^{2}$ & 0.00 & 0.00 & 0.00 & 0.00 & 0.00 & 0.00 \\
\hline Results of simulations & $\begin{array}{l}\text { Strong partisan } \\
\text { bias }(97 \%)\end{array}$ & $\begin{array}{l}\text { Strong partisan } \\
\text { bias }(94 \%)\end{array}$ & $\begin{array}{l}\text { Only partisan } \\
\text { bias }(60 \%)\end{array}$ & $\begin{array}{l}\text { Strong partisan } \\
\text { bias }(99.9 \%)\end{array}$ & $\begin{array}{l}\text { Strong partisan } \\
\text { bias }(96 \%)\end{array}$ & $\begin{array}{c}\text { Strong partisan } \\
\text { bias }(96 \%)\end{array}$ \\
\hline & $\begin{array}{l}\text { Weak partisan } \\
\text { bias }(3 \%)\end{array}$ & $\begin{array}{l}\text { Weak partisan } \\
\text { bias }(6 \%)\end{array}$ & $\begin{array}{l}\text { Strong partisan } \\
\text { bias }(40 \%)\end{array}$ & & $\begin{array}{c}\text { Only partisan } \\
\text { bias }(4 \%)\end{array}$ & $\begin{array}{c}\text { Only partisan } \\
\text { bias }(4 \%)\end{array}$ \\
\hline
\end{tabular}

Note: standard errors in parentheses. ${ }^{*} \mathrm{p}<0.01,{ }^{*} \mathrm{p}<0.05,{ }^{*} \mathrm{p}<0.10$ (one-tailed test). 


\begin{tabular}{|c|c|c|c|c|c|c|}
\hline Independent variable & $\begin{array}{l}\text { George W. Bush } \\
(2000)\end{array}$ & Al Gore & $\begin{array}{l}\text { George W. } \\
\text { Bush (2004) }\end{array}$ & $\begin{array}{l}\text { John } \\
\text { Kerry }\end{array}$ & $\begin{array}{l}\text { John } \\
\text { McCain }\end{array}$ & $\begin{array}{l}\text { Barack } \\
\text { Obama }\end{array}$ \\
\hline (1) Fairness in principle & $0.87(0.27)^{* *}$ & $0.47(0.25)^{*}$ & $0.53(0.28)^{*}$ & $0.79(0.26)^{* *}$ & $0.67(0.55)$ & $0.33(0.47)$ \\
\hline (2) Partisanship congruent with criticism & $0.99(0.27)^{* *}$ & $0.42(0.27)^{\#}$ & $1.28(0.32)^{* *}$ & $1.31(0.31)^{* *}$ & $1.63(0.66)^{* *}$ & $0.73(0.68)$ \\
\hline $\begin{array}{l}\text { (3) Fairness in principle } \times \text { Partisanship } \\
\text { congruent with criticism }\end{array}$ & $0.42(0.39)$ & $0.24(0.38)$ & $0.17(0.40)$ & $0.06(0.40)$ & $0.00(0.82)$ & $1.71(0.86)^{*}$ \\
\hline Independent & $0.52(0.36)^{\#}$ & $0.05(0.37)$ & $0.22(0.53)$ & $0.40(0.52)$ & $-0.10(1.05)$ & $0.63(0.93)$ \\
\hline Fairness in principle $\times$ Independent & $-0.00(0.52)$ & $0.26(0.52)$ & $0.76(0.68)$ & $-0.25(0.66)$ & $0.36(1.34)$ & $1.11(1.28)$ \\
\hline $\begin{array}{l}\text { View of government } \\
\text { Trust in government } \\
\text { Political Expertise }\end{array}$ & $-0.50(0.35)^{\#}$ & $0.55(0.34)$ & $-1.08(0.49)^{*}$ & $0.69(0.47)^{\#}$ & $0.03(0.98)$ & $1.37(1.12)$ \\
\hline $\begin{array}{l}\text { Political knowledge } \\
\text { Newspaper readership }\end{array}$ & $\begin{array}{r}0.60(0.33)^{*} \\
-0.33(0.24)^{\#}\end{array}$ & $\begin{aligned} & 0.97(0.33)^{* *} \\
- & 0.16(0.23)\end{aligned}$ & $\begin{array}{l}1.34(0.38)^{* *} \\
0.01(0.26)\end{array}$ & $\begin{array}{c}0.10(0.37) \\
-0.50(0.26)^{*}\end{array}$ & $\begin{aligned} & 1.65(0.78)^{*} \\
- & 0.04(0.46)\end{aligned}$ & $\begin{array}{l}0.13(0.69) \\
0.07(0.43)\end{array}$ \\
\hline $\begin{array}{l}\text { Generation } \\
\text { New Deal } \\
\text { Cold War } \\
\text { Early boomer } \\
\text { Late boomer } \\
\text { Constant }\end{array}$ & $\begin{array}{c}-0.36(0.40) \\
-0.36(0.28)^{\#} \\
0.13(0.25) \\
0.30(0.24) \\
-0.60(0.38)^{\#}\end{array}$ & $\begin{array}{l}-1.32(0.41)^{* *} \\
-1.18(0.28)^{* *} \\
-0.68(0.25)^{* *} \\
-0.20(0.23) \\
-0.63(0.35)^{*}\end{array}$ & $\begin{array}{c}-1.11(0.40)^{* *} \\
-0.53(0.27)^{*} \\
0.10(0.28) \\
-0.14(0.26) \\
-0.70(0.48)^{\#}\end{array}$ & $\begin{array}{l}-0.45(0.39) \\
-0.17(0.26) \\
-0.09(0.27) \\
-0.03(0.25) \\
-0.65(0.44)^{\#}\end{array}$ & $\begin{array}{c}-0.76(0.76) \\
-0.38(0.58) \\
-0.36(0.63) \\
0.37(0.59) \\
-1.55(0.91)^{*}\end{array}$ & $\begin{array}{l}-0.06(0.77) \\
-0.82(0.57)^{\#} \\
-0.08(0.53) \\
-0.07(0.48) \\
-1.25(0.76)^{\#}\end{array}$ \\
\hline $\begin{array}{l}\mathrm{N} \\
\text { Pseudo } \mathrm{R}^{2} \\
\text { Prob. }>\mathrm{Chi}^{2}\end{array}$ & $\begin{array}{l}621 \\
0.11 \\
0.00\end{array}$ & $\begin{array}{l}611 \\
0.08 \\
0.00\end{array}$ & $\begin{array}{l}614 \\
0.13 \\
0.00\end{array}$ & $\begin{array}{l}603 \\
0.11 \\
0.00\end{array}$ & $\begin{array}{l}166 \\
0.14 \\
0.00\end{array}$ & $\begin{array}{l}179 \\
0.18 \\
0.00\end{array}$ \\
\hline Results of simulations & $\begin{array}{r}\text { Strong partisan } \\
\text { bias }(99.9 \%)\end{array}$ & $\begin{array}{c}\text { Strong partisan } \\
\text { bias }(92 \%) \\
\text { Weak partisan } \\
\text { bias }(5 \%) \\
\text { Only partisan } \\
\text { bias }(2 \%)\end{array}$ & $\begin{array}{c}\text { Strong partisan } \\
\text { bias }(92 \%) \\
\text { Weak partisan } \\
\text { bias }(5 \%) \\
\text { Only partisan } \\
\text { bias }(2 \%)\end{array}$ & $\begin{array}{c}\text { Strong partisan } \\
\text { bias }(99 \%)\end{array}$ & $\begin{array}{c}\text { Strong partisan } \\
\text { bias }(89 \%) \\
\text { Only partisan } \\
\text { bias }(11 \%)\end{array}$ & $\begin{array}{c}\text { Strong partisan } \\
\text { bias }(69 \%) \\
\text { Only partisan } \\
\text { bias }(16 \%) \\
\text { Weak partisan } \\
\text { bias }(7 \%) \\
\text { None of the } \\
\text { models }(8 \%)\end{array}$ \\
\hline
\end{tabular}

Note: standard errors in parentheses. Ns are smaller in 2008 because the sample was divided into experimental groups (the subject of another paper). The 2008 results are from the control groups. ${ }^{* * p}<0.01,{ }^{*} \mathrm{p}<0.05,{ }^{\#} \mathrm{p}<0.10$ (one-tailed test). 
Simulation results from Table 1

Bush 2000, $\beta_{\mathrm{PF}}<0$
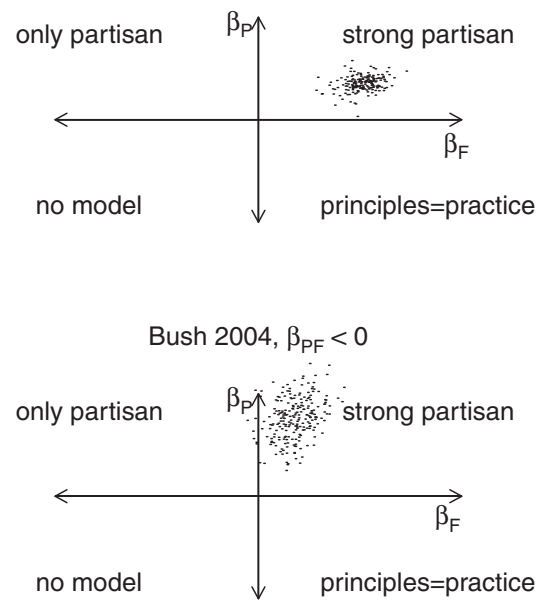

Bush 2000, $\beta_{\mathrm{PF}}>0$

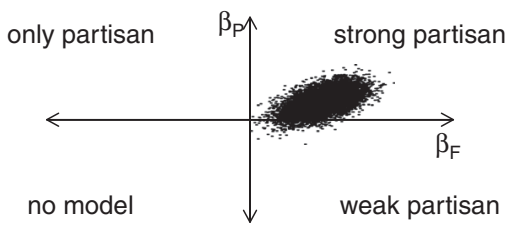

Note: Plotted points drawn from a $10 \%$ random subsample of simulated parameters

Fig. 1. Simulation results for Bush 2000 and Bush 2004 (Table 1 equations)

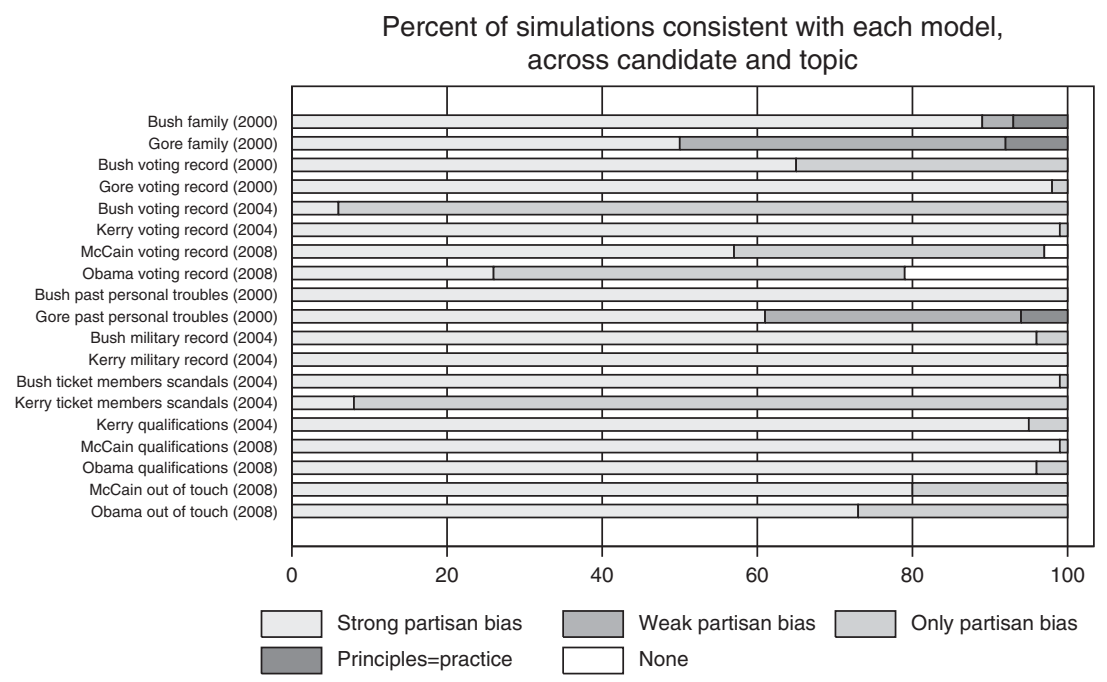

Fig. 2. Summary of biases in perceptions of fairness for the remaining nineteen criticisms

Testing across all four models simultaneously using classical hypothesis testing is not straightforward. We cannot simply rely on the statistical significance of individual coefficients, or on joint tests on the parameters of Fairness in Principle $(F)$ and Fairness in Principle $\times$ Partisanship Congruent with Criticism $(F \times P)$ because, while each of our models has expectations for the coefficients on $F, P$ and $F \times P$, we have two non-standard complications. First, we are not pitting one model against another. Rather, we want to sort through four competing models. Secondly, tests of the applicability of our 
models do not simply require joint parameter tests, but joint one-sided parameter tests. Testing whether the parameters for Fairness in Principle $=0$ and Partisanship Congruent with Criticism $=0$ is straightforward, as is testing whether Fairness in Principle $>0$. But testing whether the parameters on Fairness in Principle $>0$ and on Partisanship Congruent with Criticism $>0$ is not straightforward. ${ }^{34}$

To demonstrate the implications of the models, given these complications, we adopted the following approach: for each equation, we simulate 100,000 draws from our estimated parameters (using Clarify ${ }^{35}$ ). Figure 1 provides an example, representing two equations from Table 1. For each equation, the signs of the three parameters on $F, P$ and $F \times P$ can each be negative or positive, meaning that their possible combinations $(2 \times 2 \times 2)$ yield eight regions. The panels for each row in Figure 1 are defined by the sign of the interaction term; the left panel has a negative interaction term, while the right panel has a positive interaction term. In each panel, the $x$-axis reflects the range of the fairness parameter, whereas the $y$-axis reflects the range of the partisan congruence parameter. The quadrants are labeled with the model that is consistent with the configuration of signs of the parameters in that region. For example, if the coefficients on $F$ and $P$ are both negative, such results are not consistent with any of our four models. If the sign on $F$ is positive and the sign on $P$ is negative, then if the sign on $F \times P$ is negative, that is consistent with Principles $=$ Practice, whereas if the sign on $F \times P$ is positive, that is consistent with Weak Partisanship. In this sense then, discriminating between Principles = Practice and Weak Partisanship depends on the sign of the interaction term. Simply testing the sign of the interaction term does not work for our purposes, however, because for either model to hold, the partisan congruence parameter needs to be negative and the fairness parameter needs to be positive. If those last two conditions do not also hold, the set of parameters will lie in a quadrant consistent with a different model (or no model).

From the 100,000 draws we calculate the percent of time the simulated parameters fall into each of the eight regions, then map those percentages into our four models. ${ }^{36}$ Figure 1 compares two sets of simulated parameter estimates from Table 1, from Bush 2000 (top row) and Bush 2004 equations (lower row). ${ }^{37}$ In the Bush 2000 results, the parameter estimates are consistent with the Strong Partisan Bias model 97 per cent of the time - in the top row of Figure 1, nearly all of the points are in the upper right quadrant. A handful of points lies in the lower right quadrant, consistent with the Weak Partisan Bias model. The Bush 2004 simulations, by contrast, display a different pattern. A majority of points (60 per cent) falls in the upper left quadrant, which is consistent with the Only Partisan Bias model. A substantial portion of the simulated parameters lies in the upper right quadrant, however, so the discrimination across models is not as strong in the Bush 2004 case as in the Bush 2000 case. We indicate with which model the simulations indicate consistency in the bottom row of Table 1.

The simulations show that the results are most consistent with Strong Partisan Bias in most cases, with the Only Partisan Bias model mildly dominating in one example, for judgments of the criticism of George W. Bush in 2004. In the other five examples, the simulations fall in the quadrant indicating Strong Partisan Bias well over 90 per cent of the time. The Weak Partisan Bias model holds that if a criticism is seen as fair in principle,

\footnotetext{
${ }^{34}$ See, for example, the discussion in Wolak 1987.

35 King, Tomz, and Wittenberg 2000.

36 And a fifth possibility, which is that the results are consistent with none of our models.

37 We present only 10 per cent of the draws here to make the plots clearer.
} 
real examples of such criticism are more likely to be judged as fair when you share the partisanship of the messenger, while partisanship should not moderate the influence of fairness principles when a criticism is viewed as unfair in principle. The results in Table 1 and Figure 1 are clearly inconsistent with this model.

Instead, the simulations make it clear that even individuals who judged a subject to be off-limits in principle were affected by partisanship when it came to judging the fairness of real criticisms offered by real candidates. Compared to partisans for whom a criticism was incongruent with their dispositions, congruent partisans were considerably more likely to judge criticisms of George W. Bush, Al Gore, John Kerry, John McCain and Barack Obama as fair, even if they had deemed such criticisms to be unfair in principle. Partisans judged criticisms evaluated as fair in principle to be unfair when applied to their candidate, and similarly saw criticisms evaluated as unfair in principle to be acceptable when applied to the opposition. In four instances (George W. Bush in 2000 and 2004, John Kerry in 2004 and Barack Obama in 2008) the interaction terms show that the gap widened further between partisans for whom the criticism was congruent and incongruent when a criticism was judged as fair in principle; in the other two cases (Al Gore in 2000 and John McCain in 2008) the partisan gap was no wider when a criticism was judged as fair in principle than when it was judged as unfair in principle.

The meaning of the estimates in Table 1 can be further illustrated with some point estimates. We set the control variables at their means or modes, while allowing values for perceptions of the fairness of the attacks in principle to be set as fair or unfair, and partisanship as congruent with the attack or incongruent with the attack. Examining the estimates shows that although principles mattered in most of the examples, partisan differences were great regardless of principles. Among the respondents who viewed criticism of a candidate for talking one way and voting another as unfair in principle, there was a generally lower probability of judging the specific criticism as fair, but partisan gaps are nevertheless evident. For all candidates, the probability of an individual judging a criticism as fair was at least ten points (and as much as sixty points) greater among respondents for whom the criticism was congruent than for whom it was incongruent with their partisan affiliations. This finding demonstrates that partisan bias has the capacity to move large numbers of respondents to judge a criticism as fair rather than unfair and vice versa. The estimates also illustrate how partisan perceptions are contingent upon who is being attacked. Republicans were less likely than Democrats to view attacking Bush or McCain as fair in each election, but the relationship is reversed when the target of the criticism is Al Gore, John Kerry or Barack Obama; in these latter cases, Republicans are far more likely than Democrats to judge criticizing the candidate for 'talking one way and voting another' as fair. Moreover, the predicted probabilities when partisanship is congruent with the charge tend to be above the 0.5 threshold, which demonstrates a tendency to evaluate these criticisms as fair regardless of principles, whereas incongruent partisans fall on or below the 0.5 threshold, indicating a tendency to regard the criticisms as unfair. ${ }^{38}$

To demonstrate that these patterns are not confined to criticisms of candidates' voting records, Table 2 presents analysis of a different criticism in the three elections: taking campaign contributions from special interests such as 'big oil' or trial lawyers. Again, these results show that congruent partisans are consistently more likely to judge a criticism against the opposing party's candidate as fair, even among respondents who had

${ }^{38}$ See online Appendix Figure A-1. 
described the topic of criticism as unfair in principle. In all six examples the simulations, the results of which are presented at the bottom of the table, show that the Strong Partisan Bias model dominates. Contrary to the Only Partisan Bias model, fairness principles influence judgments of the fairness of the actual criticisms; contrary to the Weak or No Partisan Bias models, congruency of the criticism with partisanship results in consistently more generous judgments of fairness. ${ }^{39}$

Point estimates from this analysis, following the same procedure described above, show similar patterns of highly malleable application of principles. When a criticism is viewed as fair in principle it is also more likely to be judged fair in practice, but there are partisan differences both among respondents who said criticizing a candidate for taking campaign contributions from special interests is unfair and among respondents who said it is fair. The partisan gaps are also comparable to the estimates from Table 1 - about $10-50$ points. Moreover, when we examined respondents' underlying probabilities of perceiving criticism of campaign contributions as fair, there was ambivalence about this kind of attack - large numbers of respondents were close to the 0.5 probability threshold. Thus once again the gaps are sufficient to change perceptions of the acceptability of an attack in large numbers. ${ }^{40}$

Up to this point we have focused on a subset of results - criticisms of a candidate's record or the special interests to whom he is alleged to be beholden for money - in which the public tends to view the criticism as fair in principle (see Appendix Table A-4). Figure 2 shows the results from all the other criticisms. Of particular interest here are more personal criticisms, such as of the behavior of family members, which most members of the public view as off-limits. The analysis in Figure 2 shows two cases in point. The criticism is related to the behavior of family members in 2000 . Very few respondents considered this subject to be a fair topic of attack in the abstract; only 3 per cent thought it a legitimate subject for a critical ad, rising to about 10 per cent for specific examples of misbehavior by Bush and Gore family members. Figure 2 shows that even in this case, the Strong Partisan Bias model is dominant for judgments of the criticism of Bush, while the Strong and Weak Partisan Bias models are about equally applicable to the criticism of Gore. ${ }^{41}$ Thus even in such extreme cases, in which attacks violate nearly universally held norms, motivated partisans are prone to allow their predispositions to override their sense of the legitimacy of criticisms that they find so clearly objectionable in principle. This is less true of the Gore example; there is some indication that individuals who judge such a criticism unfair in principle also judge it to be unfair in practice, regardless of partisanship, but the Strong Partisan Bias model is still most applicable in half the simulations (full model results are in online Appendix III Table A-5).

The overall message of the analysis in the tables and figures is clear: partisan bias moderates principles in the vast majority of cases; the main variation relates to whether fairness principles have any discernible influence on judgments of real campaign

\footnotetext{
39 We simulated results using the same method as in Figure 1 to draw the conclusions about consistency that are presented in the last row of the table. Figures are available on request. The simulations for 2008 show somewhat less dominance of the Strong Partisan Bias model, but the smaller sample sizes for this analysis in 2008 (as explained in the notes to Table 2) may be a factor, bearing in mind the results for the same charge in other elections and the similarity between 2008 and the other two elections when the sample size is comparably large.

${ }^{40}$ A figure illustrating this is available from the authors on request.

41 Independents who viewed this type of attack as fair in principle, however, were not more likely to see it as fair in practice.
} 
criticisms. In most cases they do; the results are most often consistent with the Strong Partisan Bias model, in which principles of fairness affect judgments of fairness in practice, but partisanship colors those judgments regardless of whether the topic of criticism is deemed fair or unfair in principle. For eighteen of the thirty-one criticisms, more than 90 per cent of the simulations are consistent with Strong Partisan Bias. Of the remaining thirteen criticisms, Strong Partisan Bias dominates 50-89 per cent of the time for nine of them. Only Partisan Bias is the dominant model for the other four, although in only two of these do over 90 per cent of simulations fall in the Only Partisan Bias region.

On closer examination, the pattern in these four examples - criticisms of George W. Bush in 2004 for talking one way and voting another and of his voting record, of John Kerry via his vice presidential nominee and of Barack Obama's voting record - is that partisans who rated the topic of criticism as fair in principle but for whom the criticism was incongruent were somewhat more likely to see the actual criticism as unfair than incongruent partisans who rated the topic as unfair in principle. Among partisans for whom the criticism was congruent with their predispositions, on the other hand, we see the same patterns as in the Strong Partisan Bias model - clear partisan bias for those who judged a criticism to be fair in principle; they were also more likely to view it as fair in practice. Thus where we see results consistent with the Only Partisan Bias model, it is true to say, as we did in our description of this model, that fairness principles exert no discernible influence in our estimates. However, what emerges is more nuanced: there is an influence of fairness principles, but it is confined to congruent partisans in these examples. It is unclear why we see this pattern in these four examples and no others, but it may be that partisan supporters of a candidate are so convinced that these particular charges are untrue that fairness principles play no role in their judgments. ${ }^{42}$

The range of cases in which the type of criticism apparently invites partisan bias is considerable. Are there aspects of the claims or presentation of information that either encourage or discourage motivated processing and partisan bias? One important element of motivated processing theories concerns uncertainty about stimuli. Eileen Braman and Thomas Nelson find that 'predispositions leave their clearest mark on ambiguous stimuli' ${ }^{43}$ Uncertainty about the factual basis for claims may be more common than certainty for most individuals in attacks that contain claim and counterclaim. If we are right - that motivated reasoning is behind the patterns of judgments we observe - we would expect that manipulating their certainty, for example by presenting individuals with additional context to a criticism that suggests it is untrue, would moderate partisan bias.

In our 2004 survey we conducted an experiment in which half of the sample was asked to judge the fairness of an attack on John Kerry's military service in Vietnam (control group) - a 'Swift Boat Veterans for Truth'-style charge that Kerry did not deserve his three Purple Hearts - while the other half of the sample was presented with the same attack and given additional information from an 'independent organization' that questioned the factual accuracy of the attack (treatment group). ${ }^{44}$ To gauge the impact of this manipulation, we estimated a model identical to those in Tables 1 and 2, with the addition of a dummy variable for the half sample condition; a three-way interaction between the condition, the fairness of the criticism in principle and partisanship; and all

${ }^{42}$ Our experiment, described below, provides evidence to support this inference.

${ }^{43}$ Braman and Nelson 2007, p 943.

44 This has parallels to the fact checking provided by groups such as factcheck.org and in discussion of advertising in the news. 


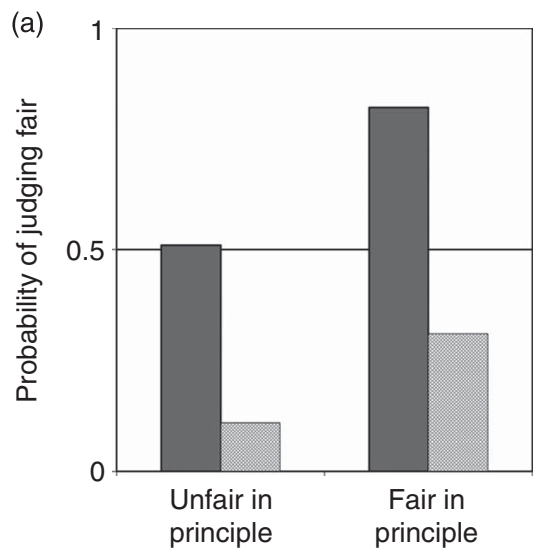

Control group (normal attack)

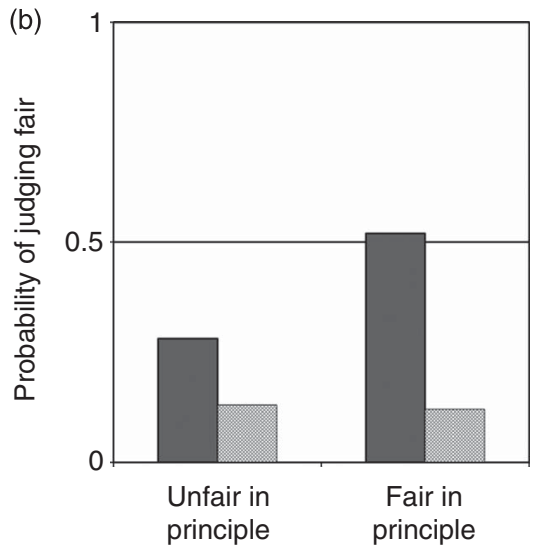

Treatment group (normal attack + additional information)

Republican identifier

Democrat identifier

Fig. 3. Point estimates of perceptions of fairness attacking John Kerry's military record: Swift Boat experiment

the combinations of two-way interactions (see Appendix III Table A-6 for the full results). Figure 3 presents point estimates to illustrate our findings.

Figure $3 \mathrm{a}$ shows estimated judgments of individuals in the control group, and Figure $3 \mathrm{~b}$ shows the treatment group, again computed separately for respondents judging such a criticism as fair game or unfair game. The patterns are consistent with the Strong Partisan Bias model, showing that principles matter - individuals who think attacking a candidate's military record is fair game are also more likely to see the Swift Boat Veterans' attack as fair - but they are applied differently depending on their congruence with partisanship. Thus Figure 3a shows that Republicans in the control group who say such an attack is unfair in principle have a greater probability of judging the specific criticism as fair than do Democrats who express the same principle (and these differences are statistically significant). Republicans in the control group who say such an attack is fair in principle also have a greater probability of perceiving the specific criticism as fair than Democrats who think such criticisms are fair in principle. For Democrats, the predicted probabilities fall below the 0.5 threshold, indicating objection to these criticisms, while the predicted probabilities for Republicans are on or above the 0.5 threshold. The differences in perceptions cover $40-50$ points of the probability scale, representing sizable gaps in perceptions.

Figure $3 \mathrm{~b}$ shows the point estimates of individuals presented with exculpatory information intended to undermine the veracity of this criticism. Beyond a general effect, in which all respondents are less likely to view the criticism as fair, partisan differences are attenuated. Among respondents who reject such attacks in principle, the gap in predicted probabilities of judging the attack as fair is more than halved - and the attenuation of the influence of congruent partisanship is statistically significant. There is also a much greater propensity, regardless of partisanship, to accept the exculpatory information and perceive the Swift Boat attacks as unfair. Although the results are less dramatic for respondents who said such criticism was fair in principle, the findings also show a lower probability of judging a criticism as fair in these circumstances and a diminishment of partisan bias. 
The simulations show that in the control condition, almost all the outcomes fall in the Strong Partisan Bias region (99.6 per cent). With the additional information the pattern changes: 64 per cent of the simulations now fall in the Strong Partisan Bias region, while the other 36 per cent are consistent with Only Partisan Bias. As Figure 3 illustrates, these results reflect that once they are exposed to exculpatory information about Kerry, Democrats do not think this negative ad is fair regardless of whether they believe such criticisms are fair or unfair in principle. Given the same information, Republicans tend to think it is a fair ad only if they believe such ads to be fair in principle, and in far lower numbers than in the absence of the additional information. This finding is consistent with the notion that partisan bias can be attenuated by providing information that is clearly contrary to the assumptions individuals need to make to reach desired conclusions.

\section{DISCUSSION AND CONCLUSION}

We have taken a hard look at how the principles that citizens hold about acceptable political speech affect judgments about negative ads in the heat of a campaign. We replicate the findings of past research on dimensions of acceptability such as fairness, civility and relevance by showing that citizens hold principles of the fairness of criticisms that accord with conventional wisdom. We go beyond earlier acknowledgment of a likely impact of partisanship and speculation about its form, however, using research designed to explicitly examine the manner and extent to which these principles affect perceptions of the fairness of criticisms of real candidates in real campaigns. We have tested four possible models: (1) that citizens object to norm violations and thus translate principles faithfully into their perceptions of real campaign criticisms, (2) that they engage in weaker or (3) stronger forms of partisan-motivated processing in which the impact of principles is moderated by partisanship or (4) that citizens engage in a form of partisan-motivated processing in which principles of fairness have no overall impact.

Our analysis has demonstrated that for most types of real campaign criticisms, partisan bias is evident among both partisans who judge the topic of criticism to be legitimate and those who view a given type of criticism as unacceptable in principle. Motivated processing associated with strong partisan bias appears to be the default behavior leading to evaluations of election campaign advertising. Only when the topic of an attack so clearly deviates from norms of fairness that very few will say it is ever fair in principle criticizing a candidate for the behavior of his family members or for past personal troubles with substance abuse - do we see much evidence of weaker partisan bias, but there is still partisan bias and we do not see this reduction in bias for all candidates.

Our research has focused solely on criticisms in presidential campaigns, but we would expect to see the same kind of partisan bias in judgments of campaign rhetoric in down-ballot races such as for the Senate and House. Indeed, to the extent that down-ballot races can be more personal in their attacks, provided those attacks do not grievously violate norms of fairness in the way that attacks on the behavior of family members appear to, there may be more room for partisan disagreement and partisan bias may be even stronger than that shown here.

What do our findings imply for previous research on perceptions of acceptable campaign rhetoric? First, they suggest that abstract fairness judgments, rendered in a partisan vacuum, tell us relatively little about perceptions in a real partisan campaign. Normative principles are not meaningless - on the whole, citizens who view an attack as beyond the pale in principle are also likely to object to such an attack in practice - but these principles are inconsistently applied. Our research points to an important disconnect 
between what citizens judge to be acceptable or unacceptable negativity and their application of such principles in reality. ${ }^{45}$

Secondly, our research leads us to question the portrayal of the public as tough and resilient to campaign rhetoric, inured to violations of the principles of fairness and civility as applied to the types of campaign ad claims they regard as fair. Although the end result of partisan bias may be the same, the process suggested by our findings is quite different: the public is partisan and thin-skinned when it comes to attacks on the candidate the partisan prefers and callous when it comes to attacks on the opposition, but in either case it is a rigid (rather than resilient) public applying principles in a very partial manner.

Thirdly, our findings suggest that different groups of voters process information about negative advertising in specific ways, and that these distinct processing strategies need to be identified and assessed in both experimental and survey studies. For example, our work shows that a very powerful form of motivated information processing operates among partisans when they encounter negative advertisements about candidates. It is likely that in studies that lack partisan cues, the substantive information presented to subjects and respondents is processed differently than in an actual electoral setting. Therefore until we are able to better identify and test these alternative information-processing mechanisms, it seems likely that many of our conclusions about the importance of negative campaign ads must remain tentative.

\section{REFERENCES}

Ansolabehere, Stephen, and Shanto Iyengar. 1995. Going Negative: How Political Advertisements Shrink and Polarize the Electorate. New York: The Free Press.

Bartels, Larry. 1998. Campaign Reform: Insights and Evidence, A Report of the Task Force on Campaign Reform. Princeton: Woodrow Wilson School of Public and International Affairs.

Braman, Eileen, and Thomas Nelson. 2007. Mechanism of Motivated Reasoning? Analogical Perception in Discrimination Disputes. Journal of Politics 51 (4):940-56.

Brooks, Deborah Jordan, and John Geer. 2007. Beyond Negativity: The Effects of Incivility on the Electorate. American Journal of Political Science 51 (1):1-16.

Faucheux, Ron. 1994. Versatile Videos: Videos as Political Campaign Tools. Campaigns and Elections 15:34.

Festinger, Leon. 1957. A Theory of Cognitive Dissonance. Evanston, IL: Row, Peterson.

Fischle, Mark. 2000. Mass Response to the Lewinsky Scandal: Motivated Reasoning or Bayesian Updating? Political Psychology 21 (1):135-59.

Freedman, Paul, and L. Dale Lawton. 2000. Campaign Advertising, Perceived Fairness, and Voter Turnout. Paper Presented at the Annual Meeting of the Midwest Political Science Association, Chicago, IL, 27-30 April.

Fridkin, Kim, and Patrick Kenney. 2008. The Dimensions of Negative Messages. American Politics Research 36 (5):694-723.

—. 2011. Variability in Citizens' Reactions to Different Types of Negative Campaigns. American Journal of Political Science 55 (2):307-25.

Geer, John. 2006. In Defense of Negativity: Attack Ads in Presidential Campaigns. Chicago: University of Chicago Press.

2012. The News Media and the Rise of Negativity in Presidential Campaigns: A New Hypothesis. Political Science 45 (3):422-7.

\footnotetext{
${ }^{45}$ Sigelman and Kugler (2003) argue that there is a disconnect between what academics perceive as 'negative advertising' and citizens' perceptions of negativity, a finding which we took seriously in our initial classifications of ads.
} 
Gutmann, Amy, and Dennis Thompson. 1998. Democracy and Disagreement. Cambridge: Harvard University Press.

Heider, Fritz. 1958. The Psychology of Interpersonal Relations. New York: Wiley.

Jamieson, Kathleen Hall. 2000. Everything You Think You Know About Politics ... And Why You're Wrong. New York: Basic Books.

Kahn, Kim Fridkin, and Patrick Kenney. 1999. Do Negative Campaigns Mobilize or Suppress Turnout? Clarifying the Relationship Between Negativity and Participation. American Political Science Review 93 (4):877-90.

King, Gary, Michael Tomz, and Jason Wittenberg. 2000. Making the Most of Statistical Analyses: Improving Interpretation and Presentation. American Journal of Political Science 44 (2):347-61.

Kunda, Zival. 1990. The Case for Motivated Reasoning. Psychological Bulletin 108 (3):480-98.

Kunda, Ziva, and Lisa Sinclair. 1999. Motivated Reasoning with Stereotypes: Activation, Application, and Inhibition. Psychological Inquiry 10 (1):12-22.

Lau, Richard, Lee Sigelman, and Ivy Brown Rovner. 2007. The Effects of Negative Political Campaigns: A Meta-Analytic Reassessment. Journal of Politics 69 (4):1176-209.

Lavine, Howard, Milton Lodge, and Kate Freitas. 2005. Threat, Authoritarianism, and Selective Exposure to Information. Political Psychology 26 (2):219-44.

Lilleker, Darren, and Jennifer Lees-Marshment, eds. 2005. Political Marketing in Comparative Perspective. Manchester: Manchester University Press.

Marcus, George, W. Russell Neuman, and Michael MacKuen. 2000. Affective Intelligence and Political Judgment. Chicago: University of Chicago Press.

Miller, Arthur. 1974. Political Issues and Trust in Government: 1964-1970. American Political Science Review 68 (3):951-72.

Mutz, Diana, and Byron Reeves. 2005. The New Videomalaise: Effects of Televised Incivility on Politically Motivated Economic Intervention. American Political Science Review 99 (1):1-16.

Redlawsk, David, Andrew Civettini, and Karen Emerson. 2010. The Affective Tipping Point: Do Motivated Reasoners Ever 'Get it'? Political Psychology 31 (4):563-93.

Rudolph, Thomas. 2006. Triangulating Political Responsibility: The Motivated Formation of Responsibility Judgments. Political Psychology 27 (1):99-122.

Sides, John, Keena Lipsitz, and Matthew Grossmann. 2010. Do Voters Perceive Negative Campaigns as Informative Campaigns? American Politics Research 38 (3):502-30.

Sigelman, Lee, and Mark Kugler. 2003. Why is Research on the Effects of Negative Campaigning So Inconclusive? Understanding Citizens' Perceptions of Negativity. Journal of Politics 65 (1):142-60.

Simon, Dan, Chadwick Snow, and Stephen Read. 2004. The Redux of Cognitive Consistency Theories: Evidence Judgments by Constraint Satisfaction. Journal of Personality and Social Psychology 86 (6):814-37.

Stevens, Daniel, John Sullivan, Barbara Allen, and Dean Alger. 2008. What's Good for the Goose is Bad for the Gander: Negative Political Advertising, Partisanship and Turnout. Journal of Politics 70 (2):527-41.

Tyler, Tom. 1990. Why People Obey the Law. New Haven: Yale University Press.

Wolak, Frank. 1987. An Exact Test for Multiple Inequality and Equality Constraints in the Linear Regression Model. Journal of the American Statistical Association 82 (399):782-93. 